\title{
Is Social Security Really Bad For Growth?*
}

\author{
Giorgio Bellettini \\ Univ ersit y of Pennsylv ania \\ and \\ Univ ersita' di Bologna
}

\author{
Carlotta Berti Ceroni \\ Colum bia Univ ersit y \\ and \\ Univ ersita' di Bologna
}

Ma y 22, 1995

\begin{abstract}
This paper develops a model of endogenous growth with overlapping generations to investigate the joint determination of social security, public investment and growth in a small open economy. We argue that a pure pay-as-you-go system provides the taxpayers with the incentives to support growth-oriented policies, which increase the future productivity of labor. We find that outcomes characterized by positive levels of intergenerational redistribution, public investment and long run growth can be sustained as subgame-perfect Nash equilibria of an infinitely repeated intergenerational game, if and only if the marginal productivity of public capital is large enough. Furthermore, we show that transfers either comove with public investment and growth or display a non-monotonic relation, where they initially increase along with public investment and growth and then decrease. (JEL, E62, H55)
\end{abstract}

We are greatly indebted to Roberto Perotti and Josè-Victor Rios-Rull for their help and encouragement. We have also benefited from comments and suggestions by Alessandra Casella, Vincenzo Denicolo', Giovanni Forni, Lorenzo Garbo, Roger Lagunoff, Andrea Moro, and Stephen Morris. All errors are ours alone. 


\section{Intro duction}

Most of the recent economic growth models predict that purely redistributive policies, such as social security programs, should depress growth through financial crowding out and the adverse incentive effects associated with distortionary taxation. On the other hand, accumulation may be positively associated with government expenditure on education and with public investment in infrastructure or other productive activities. At times where industrialized countries are confronted with the issue of establishing and maintaining a sound fiscal policy while fostering economic growth, the trade-off between productive and redistributive government expenditures becomes especially harsh and policy prescriptions calling for a redefinition of the nature and scope of the Welfare State gain advocates.

However, these predictions are not entirely supported by data. Some evidence can in fact be provided regarding the existence of a positive association between redistributive expenditures as a percentage of GDP and the long run growth rate. The following table reports the correlation coefficients between the average government redistributive expenditure as a percentage of GDP $\left(\frac{T R}{Y}\right)$, the average gross public domestic investment as a percentage of GDP $\left(\frac{I^{g}}{Y}\right)$ and the average annual growth rate of real GDP $(x)$, in a sample of 72 countries for which the relevant observations are available, in the period 1970-85.

\begin{tabular}{|c|ccc|}
\hline \multicolumn{4}{|c|}{ Table 1- Correlation Matrix } \\
\hline \hline & $x$ & $T R / Y$ & $I^{g} / Y$ \\
\hline$x$ & 1 & & \\
$T R / Y$ & 0.16 & 1 & \\
$I^{g} / Y$ & 0.17 & 0.10 & 1 \\
\hline \hline mean & 0.01 & 0.05 & 0.03 \\
$\max$ & 0.08 & 0.20 & 0.08 \\
$\min$ & -0.04 & 0.00 & 0.00 \\
\hline
\end{tabular}

The redistributive variable $T R$ is calculated as the difference between government transfers to the private sector and interest payments on the outstanding 
stock of public debt, and consists of pensions, unemployment and health benefits alone. Both redistributive expenditure and public investment appear to be positively correlated with growth. Also, redistributive expenditure and public investment are positively correlated. When other relevant effects are controlled for, including measures of the initial level of development, domestic investment (public and private), scholarization, government consumption and political instability, evidence of a positive relation between redistributive expenditure and growth is maintained. ${ }^{1}$

We believe that the positive effect of redistributive policies on accumulation suggested by data can be explained incorporating politics in a standard growth model. The bulk of the recent political economy models of growth argue that the composition of social conflicts may lead to extensive redistribution which has a depressive effect on growth. ${ }^{2}$ Though this intuition is appealing, we think that it needs qualifications. As long as redistribution plays a role in buying social consensus for growth-oriented activities, it may well foster rather than depress growth. ${ }^{3}$ Redistribution evens up the costs and benefits of growth across social classes. If redistribution makes growth socially palatable, the absence of adequate redistributive programs may fuel a deep social conflict resulting in poor economic and growth performance. The present paper explores this intuition and puts forward a motivation for why redistributive and growth-oriented policies, though competing for scarce tax revenues, might go hand in hand and bring about fast economic growth.

The situation we have in mind is one where sustained growth is generated

\footnotetext{
${ }^{1}$ Regressions displaying the average growth rate as the dependent variable and including various components of government expenditure among regressors have been proposed, among others, by Barro and Sala-y-Martin [5], Easterly [15], Perotti [22] and Sala-y-Martin [29]. SalaY-Martin [29] explicitely mentions the surprisingly positive coefficient of transfers.

${ }^{2}$ See for instance Alesina and Rodrick [1], Bertola [7], Krusell, Quadrini and Rios-Rull [20], Perotti [23], Persson and Tabellini [24].

3Sala-y-Martin [29] provides a different explanation, where pensions may increase growth if they are used to force umproductive old workers out of the production process.
} 
by public investment in capital goods. ${ }^{4}$ Public investment needs to be financed through tax revenues. The feasible level of fiscal pressure and the allocation of the governement budget to different expenditure components tends to reflect the interests of a majority of the population and is agreed upon collectively. Heterogeneous agents bear different costs and enjoy different gains in the growth process. Redistribution may help at evening out such differences, create political support for taxation and boost the tax revenues available for government expenditure.

In particular, consider a small open economy and assume that while no impediments exist to the mobility of private financial wealth across national borders, other factors of production, such as labor and public capital, are non-tradable. Heterogeneity is introduced by assuming that the economy is populated by overlapping generations of finitely-lived and non-altruistic agents living for two periods. Except for age, agents are identical. Agents work, save and pay taxes when young and receive a retirement pension benefit on top of private savings when old. Taxation falls on labor income alone. Since labor supply is inelastic, this amounts to lump-sum taxation. However, tax revenues collection is costly: this is the only source of distortion in our setup.

In this context, we argue that the entitlement to indexed-to-wages pension payments at retirement in a pure pay-as-you-go system, financed out of contributory taxation, may provide the taxpayers with the incentives to support growthoriented policies, since it makes them able to reap some of the benefits deriving from increased taxation that would otherwise be inaccessible to them. In the absence of intergenerational redistribution, sustained growth would be politically impracticable, though technically and economically feasible. Indeed, the benefits deriving from (public investment driven) growth are appropriable by taxpayers through two channels: the increased marginal productivity of private capital and the growth of unit wages. The latter is lost at retirement. The former is not even at work, in a small open economy with complete capital mobility, since the interest rate is fixed at the world-wide level. ${ }^{5}$ Therefore the agreement to allocate some

\footnotetext{
${ }^{4}$ Public investment in capital goods includes investment in infrastructure, health facilities and human capital.

${ }^{5}$ In the context of an overlapping generation model where partially altruistic agents vote on the level of public education in the absence of other forms of intergenerational redistribution and
} 
share of the tax revenues to intergenerational redistribution in each period can render otherwise impraticable positive levels of taxation and public investment politically viable and allow the economy to take-off.

Notice that a fully funded system would not achieve the same result, since the rate of return from that system is exogenous and equal to the worldwide interest rate.

The relation between redistribution, social cohesion and growth we come to describe has been proposed by political scientists and economists in different contexts. The development of social security systems in continental Europe and the U.S. between the nineteenth and twentieth centuries has been explained as an atteimpt of the ruling class to bind the workers' to the State, in response to the social unrest associated to fast economic growth and the spreading of the Socialist movement (Rimlinger [25]). This idea also permeates the Solidaristic approach to development of the small North-European countries, where the expansion of the Welfare State has been an important political concomitant of liberal trade and growth-oriented policies (Katzenstein [16], [17]). Besides, the poor economic performance of some Latin American countries is sometimes explained as a consequence of the deep social conflict that, in the virtual absence of a Welfare State evening out the effects of economic growth, leads to frequent upsurges of social discontempt that put growth and market-oriented policies at stake (Sachs [26]).

Our interpretation of the social security system as an institution capable of enlarging the (political) support for growth-oriented policies, is also very close in spirit to the notion of Welfare State delineated by Gary Becker in his Treatise on the family. As Becker puts it (pp. 370, [6]): "...expenditures on the elderly are part of a social compact between generations. Taxes on adults help finance efficient investments in children. In return, adults receive public pensions and where growth is led by human capital accumulation, Boldrin [10] shows that no-growth equilibria can arise also in the case of closed economies, at least at the initial stages of development. This happens because the return from investment in public education, from the point of view of taxpayers, is low when the share of income devoted to investment in physical capital is small relative to its return. 
medical payments when old...Public expenditure on the elderly, together with public investment, can fill the void left by the breakdown of social norms in modern societies..." that imposed on the adult members of the family the burden of investing in the offspring's assets and of supporting the elderly. Becker does not model formally how such intergenerational agreement should emerge and be enforced, nor does he explain in detail its characteristics or the consequences for growth of its introduction, which is indeed our scope.

We think of fiscal policies as endogenous variables which are determined through the aggregation of individual preferences by some mechanism such as majority voting. In the context of dynamic models, a major conceptual problem arises. The difficulty has to do with the relation between current and future policy choices, the interaction between policy and state variables and with the way expectations on future policies are formed.

On one hand, it is well known from the public choice literature on social security, that, if the future level of pension benefits is believed to be independent of the current one (agents take future policy choices as given, when deciding on the current ones), a positive level of redistribution can never arise as a political equilibrium, unless the old are politically predominant. Since there are no incentives to pay pensions at any point in time, the only rational expectation on the future level of transfers is zero. In our setup this implies that public investment is also set equal to zero.

In order to obtain a relation between transfers, public investment and growth, we need to extend the agents' rationality to encompass strategic behaviour. In other words, we need to assume that the agents recognize that future policy choices depend on the current ones. However, the interaction between state variables and the agents' strategic incentives quickly makes the analysis very complicated in general, even in standard dynamic models. ${ }^{6}$ This is where our simple setup helps. In fact, most complications can be avoided in our model due to the small open economy assumption and preferences homotheticity.

\footnotetext{
${ }^{6}$ For a rigorous analysis of dynamic politico-economic equilibria, see Krusell, Quadrini and Rios-Rull [20] and Krusell and Rios-Rull [19].
} 
An analysis of the intertemporal credibility problem of social security was developed by Sjobolm [28] in a OLG model without production and accumulation where benefits and contributions are determined through a majority vote rule. The most preferred tax rate by the median voter is shown to be sustainable as a subgame-perfect Nash equilibrium in a repeated game. ${ }^{7}$

Very recently, Boldrin and Rustichini [11] extended the analysis to show that a pay-as-you-go system can be supported as the subgame-perfect Nash equilibrium of an infinitely repeated game in a standard OLG model with capital accumulation where the level of social security is chosen through majority voting. Within this model, they investigate the dynamic properties of the social security system and the impact of changes in the exogenous growth rate of population.

Our contribution uses a similar approach in a OLG model with endogenous growth to study the joint determination of productive expenditures and transfers, in order to shed light on the relationship between the pay-as-you-go system and the rate of growth of the economy. In particular, at the beginning of each period (that is, in each stage of the game), the young, who act as dictators, choose the shares of their labor income that they want to devote to pensions for the current old and to investment in public capital. We can show that, whenever the potential gains from growth are large enough, an outcome characterized by sustained balanced growth can be supported as a subgame-perfect Nash equilibrium of the infinitely repeated intergenerational game. The credible threat to be denied the entitlement to pensions in old age by the following generation deters the current young from defecting by not paying pensions to the coexisting old. ${ }^{8}$

This equilibrium can be interpreted as the creation by the society of an informal constraint (social norm) such that the young transfer resources to the old and carry out investments that will benefit the future generations, in exchange for the old's previous investment and expecting the future generation to follow the same

${ }^{7}$ The first author to analyze a median voter model of social security was Browning [12]. A survey of models of voting for social security that followed and extended Browning's contribution can be found in Boadway and Wildasin [8]. See also Tabellini [30].

${ }^{8}$ Notice that the agents that are called on to act in each stage of the game are in every respect identical. Therefore, in order to characterize their optimal course of action, we simply need to solve standard maximization problems. 
norm.

The main results of our model can be summarized as follows:

- If the strategies of the players are history-independent, that is, the young do not take into account the past histories when choosing their actions, the only subgame-perfect Nash equilibrium is such that there is no public investment, no redistribution and the economy experiences no growth.

- If and only if the marginal productivity of public capital is large enough, stationary outcomes characterized by positive levels of redistribution, public investment and a positive rate of long-run growth can be sustained as subgame-perfect Nash equilibria of the infinitely repeated intergenerational game. In particular, we study those fiscal policies that maximize the welfare of the young, who behave as dictators at each stage of the game.

- In a neighborhood of the equilibrium with positive growth: (a) the share of public investment in labor income and the rate of growth comove in response to changes in the exogenous variables; (b) the share of transfers in labor income either comoves with growth or displays a non-monotonic relation where transfers initially increase along with growth and then decrease.

The structure of the paper is as follows. Section 2 sets out the model and the policy game and discusses both the competitive equilibrium and the equilibrium of the game. Section 3 presents the comparative statics results. Section 4 concludes.

\section{The model}

\subsection{The e conomic e nvironme nt}

We analyze a small open economy with two-period lived overlapping generations agents. Population is assumed to be constant: in each period, an equal mass of young and old is alive, which we both normalize to one. Labor is supplied inelastically by the young.

The utility of an individual born at time $t$ is given by: 


$$
U^{t}\left(c_{t}^{t}, c_{t+1}^{t}\right)=\log \left(c_{t}^{t}\right)+\beta \log \left(c_{t+1}^{t}\right)
$$

where $c_{s}^{t}$ is the consumption at time $s$ of an agent born at time $t$.

Output is produced according to the following production function:

$$
Y_{t}=\Delta L_{t}^{\alpha} K_{t}^{1-\alpha} g_{t}^{\alpha}
$$

where $L$ denotes aggregate labor, $K$ denotes aggregate private capital, $g=G / L$ is the amount of public capital per worker and $\Delta$ is the total factor productivity which is assumed to be constant. Following Barro [3], we assume that public services are rival and excludable.

The laws of motion of private and public capital are given by:

$$
\begin{aligned}
& K_{t+1}=\left(1-\delta_{K}\right) K_{t}+I_{t}^{p} \\
& G_{t+1}=\left(1-\delta_{G}\right) G_{t}+I_{t}^{g}
\end{aligned}
$$

Private capital can move between the foreign and the domestic production sector at no cost. The worldwide interest rate on financial assets is denoted by $\bar{r} \geq 0$.

\subsection{The game}

In our model, the young consume, save and may use part of their labor income to finance investment in public capital and transfers to the old. We will analyze the choice of these two fiscal policies in the context of an infinitely repeated intergenerational game. Let us begin by describing the "constituent" stage game $\Gamma$. At time $t$, the young, who represent the majority of the population, decide what fraction of their labor income to devolve to public investment and to transfers. These fractions (tax rates) are denoted by $\tau_{i, t}$ and $\tau_{t r, t}$.

Notice that, in each stage of the game, the old play no role in the determination of the equilibrium policies. This is in line with the main purpose of the paper, that is to investigate the joint determination of transfers and productive expenditures, in relation with the rate of growth, in order to find an explanation for why even the young (i.e. the taxpayers) may decide to support an equilibrium with positive 
transfers. In this context, the preferences of the old for the maximum level of redistribution would not add much insight. ${ }^{9}$

Let $A_{t}=\left(\tau_{i, t}, \tau_{t r, t}\right)$ be the action space with $\tau_{i, t}, \tau_{t r, t} \geq 0$ and $\tau_{t} \equiv \tau_{i, t}+\tau_{t r, t} \leq 1$. We will consider a repeated game with perfect information where players can observe all previous actions. Thus, let $h_{t}=\left(\tau_{i 0}, \tau_{t r 0}, \tau_{i 1}, \tau_{t r 1}, \ldots, \tau_{i, t-1}, \tau_{t r, t-1}\right)$ be the history of the game at the end of stage $t-1$. Furthermore, we let $h_{0}=\emptyset$.

In this setting, a strategy for the young is a contingent plan of how to play in each stage $t$ for possible history $h_{t}$. If we denote with $H_{t}$ the set of all possible histories $h_{t}$, a strategy $\sigma_{t}$ is a map from the set $H_{t}$ to the action space $A_{t}$, that is, $\sigma_{t}\left(h_{t}\right) \in A_{t}$ for all $h_{t}$.

For every history $\left(\tau_{i 0}, \tau_{t r 0}, \ldots, \tau_{i, t}, \tau_{t r, t}, \ldots\right)$ of actions, the payoff to each player $t$ is given by her lifetime utility, evaluated at the competitive equilibrium with $\left(\tau_{i, t}, \tau_{t r, t}\right)$ and $\left(\tau_{i, t+1}, \tau_{t r, t+1}\right)$.

\subsection{The e conomic equilibrium}

We will now characterize the competitive equilibrium of our economy, given a sequence of histories $\left\{h_{t}\right\}_{t=0}^{\infty}$.

An agent born at time $t$ solves the following maximization problem:

$$
V^{t}=\max _{c_{t}^{t}, c_{t+1}^{t}}\left\{\log \left(c_{t}^{t}\right)+\beta \log \left(c_{t+1}^{t}\right)\right\}
$$

subject to:

$$
\begin{aligned}
& c_{t}^{t}=w_{t}\left(1-\tau_{t}\right)-s_{t} \\
& c_{t+1}^{t}=s_{t}(1+\bar{r})+T R_{t+1}
\end{aligned}
$$

where $T R_{t+1}=\tau_{t r, t+1}\left(1-\tau_{i, t+1}-\tau_{t r, t+1}\right) w_{t+1}$.

Here, we assume that there are convex costs in collecting taxes; if the young at time $t$ put aside $\tau_{t}$ of their labor income for public expenditures, only $\tau_{t}^{\prime} \equiv\left(\tau_{t}-\tau_{t}^{2}\right)$ is available to finance public investment and/or lump-sum transfers to the old.

\footnotetext{
${ }^{9}$ If we assumed a positive rate of growth of population, at each point in time the young would be the majority of the population. We could then define the equilibrium policies as the outcome of a majority rule vote.
} 
Assuming also that there is no borrowing, the actual levels of public investment and transfers are thus given by:

$$
\begin{aligned}
& I_{t}^{g}=\eta_{t} \tau_{t}^{\prime} w_{t} \\
& T R_{t}=\left(1-\eta_{t}\right) \tau_{t}^{\prime} w_{t}
\end{aligned}
$$

where $\eta_{t} \equiv \tau_{i, t} / \tau_{t}$ and $\left(1-\eta_{t}\right) \equiv \tau_{t r, t} / \tau_{t}$. Notice that both the level of public investment and the level of transfers can be written in terms of $\tau_{i, t}$ and $\tau_{t r, t}$. In particular, we have:

$$
\begin{gathered}
I_{t}^{g}=\left[\tau_{i, t}\left(1-\tau_{i, t}-\tau_{t r, t}\right)\right] w_{t} \\
T R_{t}=\left[\tau_{t r, t}\left(1-\tau_{i, t}-\tau_{t r, t}\right)\right] w_{t}
\end{gathered}
$$

The solution to problem (2.5) yields the following saving function:

$$
s\left(\bar{r}, w_{t} ; \tau_{t}, T R_{t+1}\right)=\frac{\beta}{1+\beta} w_{t}\left(1-\tau_{t}\right)-\frac{T R_{t+1}}{(1+\beta)(1+\bar{r})}=s_{t}
$$

Private financial wealth at the beginning of period $t+1, A_{t+1}$, is thus given by the savings of the young at time $t$, namely $A_{t+1}=s\left(\bar{r}, w_{t} ; \tau_{t}, T R_{t+1}\right)$. From first order conditions for profit maximization we get:

$$
\begin{aligned}
w_{t} & =\alpha Y_{t} \\
q_{t} & =(1-\alpha) \frac{Y_{t}}{K_{t}}
\end{aligned}
$$

where $q_{t}$ is the rental rate of capital. Equilibrium conditions on the goods and assets markets imply:

$$
\begin{gathered}
\Delta F_{t+1}=F_{t+1}-F_{t}=S_{t}-I_{t} \\
q_{t}=\delta_{K}+\bar{r}
\end{gathered}
$$

where $S_{t}$ and $F_{t}$ respectively denote aggregate savings and the stock of net foreign assets held by the private sector at time $t$ and where $F_{t}=A_{t}-K_{t}$. It can easily be verified that the competitive equilibrium implies ${ }^{10}$ :

\footnotetext{
${ }^{10}$ From now on, we will set $\delta_{G}=0$.
} 


$$
\begin{aligned}
& \frac{K_{t}}{G_{t}}=\kappa=\left[\Delta\left(\frac{1-\alpha}{\bar{r}+\delta_{K}}\right)\right]^{\frac{1}{\alpha}} \\
& \frac{Y_{t}}{G_{t}}=\phi=\left(\frac{1-\alpha}{\bar{r}+\delta_{K}}\right)^{\frac{1-\alpha}{\alpha}} \Delta^{\frac{1}{\alpha}}
\end{aligned}
$$

Let $x_{t}^{Z}$ denote the rate of growth of $Z$. By observation of (2.14) and (2.15) it should be clear that, in equilibrium, $x_{t}^{K}=x_{t}^{Y}=x_{t}^{G}=x_{t} \forall t$. The economy's dynamics in equilibrium is characterized by:

$$
\begin{aligned}
\Delta G_{t+1} & =\tau_{i, t}\left(1-\tau_{i, t}-\tau_{t r, t}\right) \alpha \kappa^{1-\alpha} G_{t} \\
\Delta F_{t+1} & =\left[\left(\varsigma_{t}-\frac{\varsigma_{t-1}}{1+x_{t}}\right)-x_{t} \kappa\right] G_{t}
\end{aligned}
$$

where:

$$
\varsigma_{t}=\frac{s\left(\bar{r}, w_{t} ; \tau_{t}, T R_{t+1}\right)}{G_{t}}
$$

Defining the Balanced Growth Path (BGP) as the locus where all variables grow at a constant (possibly common) rate and $\tau_{t}=\tau \forall t$, it can be verified that constancy of policy variables over time, i.e. $\tau_{i, t}=\tau_{i}$ and $\tau_{t r, t}=\tau_{t r} \forall t$, is both necessary and sufficient for the economy to move along a stationary path with sustained growth. It is also immediate to recognize that, along the BGP, $x^{F}=x^{K}=x^{Y}=x^{G}=x$, where the equation for the rate of growth is given by:

$$
x=\tau_{i}\left(1-\tau_{i}-\tau_{t r}\right) \alpha \phi
$$

In our model, growth is driven by the accumulation of capital in the public sector, which is financed out of tax revenues on labor income. This implies that, given the share of GDP to be devoted to public investment at each point in time, the equilibrium rate of growth is increasing with the average product of public capital in production, $\phi$, which is constant over time and is exogenously determined by the worldwide interest rate $\bar{r}$ and the technological parameters, $\delta_{K}, \Delta$ and $\alpha$. Notice that, along stationary paths, the ratio of public investment to GDP, $\tau_{i}\left(1-\tau_{i}-\tau_{t r}\right)$, is constant, so that the technology for the accumulation of public capital exhibits constant returns. 
Therefore, given policy variables, the equilibrium rate of growth is increasing with the equilibrium marginal productivity of public capital $\alpha \phi$. Given $\alpha$, changes in the exogenous variables that trigger an increase in the average productivity of public capital, $\phi$, stimulate growth. Instead, the overall effect of an increase in $\alpha$ on growth is a priori indeterminate. In fact, although increases in $\alpha$ raise taxable income and foster growth, the effect on the average product $\phi$ may turn out to be negative.

Given the marginal productivity of public capital, growth is increasing with the share of public investment in labor income, $\tau_{i}\left(1-\tau_{i}-\tau_{t r}\right)$, which in turn depends on policy variables. An increase in $\tau_{i}$ has a twofold effect on growth: on one hand, it increases the share of tax revenues allocated to public investment and stimulates growth; on the other hand, it depresses growth through the higher inefficiency of taxation. An increase in redistribution, as implied by an increase in $\tau_{t r}$, unambiguously depresses growth, since it both reduces the share of revenues allocated to public investment and increases the collection costs of taxes. Nevertheless, as we will extensively show, there cannot exist an equilibrium with positive growth and no redistribution.

Let us now characterize the economic equilibrium that arises when all histories of previous actions are given by the null vector, that is, $h_{t}=(0,0, \ldots . .0)$ for all $t$. From (2.17), it is immediate to verify that, in this case, there is no economic growth and the equilibrium allocations in every period are given by:

$$
\begin{gathered}
\underline{c}^{y}=\frac{1}{1+\beta} \alpha Y_{0} \\
\underline{c}^{\circ}=\left(\frac{\beta}{1+\beta} \alpha Y_{0}\right)(1+\bar{r})
\end{gathered}
$$

where $Y_{0}$ is the given initial level of output, $c^{y}$ and $c^{\circ}$ denote consumption when young and old, respectively.

\subsection{Equilibria of the game}

Going back to the game $\Gamma$ that we described above, assume now that every young generation adopts a history-independent strategy. In other words, in each period the selected actions (policies) do not depend on the past realizations of actions. 
In this case, we can immediately conclude that the only subgame-perfect Nash equilibrium of the infinitely repeated game $\Gamma(\infty)$ is to set $\tau_{i, t}=\tau_{t r, t}=0$, for all $t$. In fact, if future actions will be independent of the current ones, there is no incentive whatsoever for the young to carry the cost of paying transfers to the old. Consequently, the young have no interest to invest in public capital as well, since they anticipate that future generations will behave in the same way so that they will not receive pensions when old. Thus, we can summarize this discussion as follows:

Proposition 1. If every generation adopts a history-independent strategy, the only subgame-perfect Nash equilibrium of the infinitely repeated game $\Gamma(\infty)$ is $\sigma^{*}=(0,0)$.

In conclusion, if there is no link between past and current policies, the young will neither invest in public capital nor pay transfers to the old, the economy will experience no growth and the consumption allocations will be equal to $\underline{c}^{y}$ and $\underline{c}^{o}$.

Clearly, this equilibrium is not very satisfactory. More generally, actions are function of the history of the game. Thus, our next step will be to allow agents to adopt history-dependent strategies and to characterize the equilibrium outcomes in this case; in particular, we will show that there are cases where it is possible to construct equilibrium strategies such that the outcome of the game will yield strictly positive values for both $\tau_{i, t}$ and $\tau_{t r, t}$, and all generations will be better off than in the equilibrium that we have just described.

Consider first the following equilibrium candidate of our game:

$$
\begin{array}{ll}
\left(\tau_{i}^{*}, \tau_{t r}^{*}\right)=\underset{\tau_{i}, \tau_{t r}}{\arg \max }\left\{\log \left[W\left(\tau_{i}, \tau_{t r} ; \bar{r}, X\right) w_{t}\right]+C\right\} \\
\text { s.t. } & W\left(\tau_{i}, \tau_{t r} ; \bar{r}, X\right)=\left[\left(1-\tau_{i}-\tau_{t r}\right)\left(1+\bar{r}+\tau_{t r}\right)+\tau_{i} \cdot \tau_{t r}\left(1-\tau_{i}-\tau_{t r}\right)^{2} X\right] \\
& \tau_{i} \geq 0 \quad \tau_{t r} \geq 0 \quad \tau_{i}+\tau_{t r} \leq 1
\end{array}
$$

where $X \equiv \alpha \phi$ represents the marginal productivity of public capital and $C$ is a function of parameters.

In words, $\tau_{i}^{*}$ and $\tau_{t r}^{*}$ maximize the indirect utility function of the young, when future policies are restricted to be equal to the current ones. Clearly, the indirect 
utility is obtained by plugging the optimal saving function (2.10) in the utility function (2.5); furthermore, it is easy to show that the couple $\left(\tau_{i}^{*}, \tau_{t r}^{*}\right)$ that solves (2.19) is the same that maximizes the function $W\left(\tau_{i}, \tau_{t r} ; \bar{r}, X\right)$.

Notice that $\tau_{i}^{*}$ and $\tau_{t r}^{*}$ can be seen as the efficient steady state tax rates, in the sense that they maximize the welfare of each generation of taxpayers. Notice also that the solution to the problem (2.19) is time independent, given the constancy of the interest rate $\bar{r}$ and of the equilibrium marginal productivity of public capital $X$.

In the construction of the equilibrium strategy, we will introduce another policy outcome, which maximizes the indirect utility of the young when they do not pay transfer to (i.e. punish) the old, but nevertheless expect that the following generation will select the efficient policies $\tau_{i}^{*}$ and $\tau_{t r}^{*}{ }^{11}$ We denote this outcome as $\overline{\tau_{i}}$, where:

$$
\begin{aligned}
& \overline{\tau_{i}}=\underset{\tau_{i}}{\arg \max }\left\{\left(1-\tau_{i}\right)(1+\bar{r})+\tau_{t r}^{*}\left(1-\tau_{i}^{*}-\tau_{t r}^{*}\right)\left[1+\tau_{i}\left(1-\tau_{i}\right) X\right]\right\} \\
& \text { s.t. } \quad 0 \leq \tau_{i} \leq 1
\end{aligned}
$$

Assume now that the young at time $t$ adopt the following strategy, that we will denote by $\sigma_{t}^{*}\left(h_{t}\right)$ :

1. if $h_{t}=\emptyset, \sigma_{t}^{*}=\left(\overline{\tau_{i}}, 0\right)$

2. if $h_{t}=\left(\cdot, \tau_{i}^{*}, \tau_{t r}^{*}\right), \sigma_{t}^{*}=\left(\tau_{i}^{*}, \tau_{t r}^{*}\right)$

3. if $h_{t}=\left(\cdot, \tau_{i}^{\prime}, \tau_{t r}^{\prime}\right)$, with either $\tau_{i}^{\prime} \neq \tau_{i}^{*}$ or $\tau_{t r}^{\prime} \neq \tau_{t r}^{*}$ or both, count the number of consecutive periods up to $t-1$ included with $t=0$ excluded, where $\tau_{i} \neq \tau_{i}^{*}$ and/or $\tau_{t r} \neq \tau_{t r}^{*}$. Let this number be denoted by $N$ :

1. if $N$ is even, $\sigma_{t}^{*}=\left(\tau_{i}^{*}, \tau_{t r}^{*}\right)$

2. if $N$ is odd, $\sigma_{t}^{*}=\left(\overline{\tau_{i}}, 0\right)$.

In words, we constructed a strategy such that, at any point in time $t$, if the old did not "cooperate" in the previous period (i.e. they did not play $\tau_{i}^{*}, \tau_{t r}^{*}$ ),

\footnotetext{
${ }^{11}$ It is easy to verify, by observation of 2.19 and 2.20 , that $\bar{i} \geq i^{*}$.
} 
they are punished by the current young, unless the old had deviated because they were punishing generation $t-2$ for deviating. After the punishment period, the "good" equilibrium is immediately restored.

If every generation adopts the strategy $\sigma_{t}^{*}\left(h_{t}\right)$, the outcome of the infinitely repeated game will be $\left(\tau_{i}^{*}, \tau_{t r}^{*}\right)$ for all $t$, expect for $t=0$, where the outcome is $\left(\overline{\tau_{i}}, 0\right)$. Notice that, there is actually an infinite number of stationary outcomes with positive $\tau_{i}$ and $\tau_{t r}$ which can be supported as a subgame-perfect Nash equilibrium, using the strategy that we described before. In particular, we can show a Folk-theorem-like result where all individually rational outcomes can be sustained as subgame-perfect Nash equilibria. However, the selected equilibrium outcome $\left(\overline{\tau_{i}}, 0, \tau_{i}^{*}, \tau_{t r}^{*}, \tau_{i}^{*}, \tau_{t r}^{*}, \ldots\right)$ is, by construction, the one that maximizes the welfare of the agents who are the majority of the population in each stage of the game.

From now on, we will limit the analysis only to the selected equilibrium $\left(\overline{\tau_{i}}, 0, \tau_{i}^{*}, \tau_{t r}^{*}, \tau_{i}^{*}, \tau_{t r}^{*}, \ldots\right)$, which becomes the equilibrium of our model.

In order to prove that the strategy $\sigma_{t}^{*}\left(h_{t}\right)$ is a subgame-perfect Nash equilibrium of the infinitely repeated game $\Gamma(\infty)$, we need a preliminary result about the necessary and sufficient condition for the existence of an interior solution to the maximization problem (2.19).

Notice first that the first order conditions of (2.19) are given by:

$$
\begin{gathered}
W_{\tau_{i}}=-\left(1+\bar{r}+\tau_{t r}^{*}\right)+\tau_{t r}^{*}\left(1-\tau_{i}^{*}-\tau_{t r}^{*}\right) X\left(1-3 \tau_{i}^{*}-\tau_{t r}^{*}\right)=0 \\
W_{\tau_{t r}}=-\left(1+\bar{r}+\tau_{t r}^{*}\right)+\left(1-\tau_{i}^{*}-\tau_{t r}^{*}\right)+\tau_{i}^{*}\left(1-\tau_{i}^{*}-\tau_{t r}^{*}\right) X\left(1-\tau_{i}^{*}-3 \tau_{t r}^{*}\right)=0
\end{gathered}
$$

These conditions can be explained intuitively as follows. In our model there exist two alternative forms of investment, in private or public capital. The net rate of return on the former, in equilibrium, is exogenously determined by the worldwide interest rate $\bar{r}$, while the gross rate of return on the latter is endogenous and corresponds to the ratio between the pension received and the taxes paid by each generation, that is $\frac{\tau_{t r}\left(1-\tau_{i}-\tau_{t r}\right)\left[1+\tau_{i}\left(1-\tau_{i}-\tau_{t r}\right) X\right]}{\tau_{i}+\tau_{t r}}$. Each dollar levied to finance public investment or social security correspondingly reduces the total amount of resources available for investment in private capital. The marginal opportunity cost of increasing any of the tax rates is therefore given by $\bar{r}$. Instead, 
the marginal benefit of increasing any of the tax rates is given by the marginal net return from investment in public capital, that is the marginal increase in pension income minus one. By conditions (2.21)-(2.22), $\tau_{i}^{*}$ and $\tau_{t r}^{*}$ are such that the marginal cost of increasing each of the tax rates is equal to the marginal benefit of increasing it, or, equivalently, $\tau_{i}^{*}$ and $\tau_{t r}^{*}$ are such that the marginal net rate of return from investment in public capital is equal to the net rate of return from investment in private capital and to the world-wide interest rate $\bar{r}$.

Although (2.21)-(2.22) form a non-linear system in $\tau_{i}$ and $\tau_{t r}$, and closed form solutions for $\tau_{i}^{*}$ and $\tau_{t r}^{*}$ cannot be found, we are nonetheless able to derive some results which allow us to characterize the solution to the problem of the young.

First of all, note that $\tau_{i}^{*}$ and $\tau_{t r}^{*}$ bear the relation:

$$
\tau_{i}^{*}\left(1-\tau_{i}^{*}\right) X=\tau_{t r}^{*}\left(1-\tau_{t r}^{*}\right) X-1
$$

as it can be easily verified by subtracting (2.21) from (2.22). Second, we can show that:

Le mma 1. If the solution to the problem of the middle-aged (2.19) lies on the boundary, then the solution is $\left(\tau_{i}^{*}, \tau_{t r}^{*}\right)=(0,0)$.

Proof. Set $\tau_{t r}=0$. Then from $(2.21), W_{\tau_{i}}=-(1+\bar{r})<0$, which implies $\tau_{i}^{*}=0$. Now, set $\tau_{i}=0$. Again, from (2.22), $W_{\tau_{t r}}=-\left(\bar{r}+2 \tau_{t r}\right)<0$, which implies $\tau_{t r}^{*}=0$. Finally, if $\tau_{i}+\tau_{t r}=1$, both $W_{\tau_{i}}$ and $W_{\tau_{t r}}$ tend to $-\infty$.

The intuition for this result is pretty obvious. When there is no investment in public capital and consequently no growth, as it is implied by setting $\tau_{i}=0$, the economy is dynamically efficient, as long as $\bar{r} \geq 0$, and there is no welfare gain for the young from the introduction of a social security system. Besides, in the absence of pensions $\left(\tau_{t r}=0\right)$, the young are never willing to finance growth. This depends on the small open economy and complete capital mobility assumptions which imply that public investment has no effect on the equilibrium interest rate.

Third, we can show that: 
Le mma 2. For $X$ approaching infinity, the solution of the problem of the middle aged $(2.19)$ is $\left(\tau_{i}^{*}, \tau_{t r}^{*}\right)=\left(\frac{1}{4}, \frac{1}{4}\right)$.

Proof. Note that $W\left(\tau_{i}, \tau_{t r} ; \bar{r}, X\right)=\Phi\left(\tau_{i}, \tau_{t r} ; \bar{r}\right)+X \Psi\left(\tau_{i}, \tau_{t r}\right)$, where $\Phi\left(\tau_{i}, \tau_{t r} ; \bar{r}\right)=$ $\left(1+\bar{r}+\tau_{t r}\right)\left(1-\tau_{i}-\tau_{t r}\right)$ and $\Psi\left(\tau_{i}, \tau_{t r}\right)=\tau_{i} \cdot \tau_{t r}\left(1-\tau_{i}-\tau_{t r}\right)^{2}$. It is easily verified that the function $\Psi\left(\tau_{i}, \tau_{t r}\right)$ has a unique maximum at $\left(\frac{1}{4}, \frac{1}{4}\right)$, or equivalently, that there exists $\varepsilon>0$ such that $\Psi\left(\frac{1}{4}, \frac{1}{4}\right)-\Psi\left(\tau_{i}, \tau_{t r}\right) \geq C_{\varepsilon},\left(\tau_{i}, \tau_{t r}\right) \notin$ $D\left(\left(\frac{1}{4}, \frac{1}{4}\right), \varepsilon\right)$. Now note that $W\left(\frac{1}{4}, \frac{1}{4} ; \bar{r}, X\right) \geq X \Psi\left(\frac{1}{4}, \frac{1}{4}\right)$, since $\Phi\left(\tau_{i}, \tau_{t r} ; \bar{r}\right) \geq 0$. Moreover $W\left(\tau_{i}, \tau_{t r} ; \bar{r}, X\right) \leq \max \Phi\left(\tau_{i}, \tau_{t r} ; \bar{r}\right)+X \Psi\left(\tau_{i}, \tau_{t r}\right)$ and $W\left(\frac{1}{4}, \frac{1}{4} ; \bar{r}, X\right)-$ $W\left(\tau_{i}, \tau_{t r} ; \bar{r}, X\right) \geq X\left[\Psi\left(\frac{1}{4}, \frac{1}{4}\right)-\Psi\left(\tau_{i}, \tau_{t r}\right)\right]-\max \Phi\left(\tau_{i}, \tau_{t r} ; \bar{r}\right), \forall\left(\tau_{i}, \tau_{t r}\right) \notin D\left(\left(\frac{1}{4}, \frac{1}{4}\right), \varepsilon\right)$. Note also that the LHS term in the last inequality is strictly positive for $X$ large enough. Then, for $X$ large enough, $W\left(\frac{1}{4}, \frac{1}{4} ; \bar{r}, X\right)-W\left(\tau_{i}, \tau_{t r} ; \bar{r}, X\right)>0, \forall$ $\left(\tau_{i}, \tau_{t r}\right) \notin D\left(\left(\frac{1}{4}, \frac{1}{4}\right), \varepsilon\right)$, or, equivalently, $W\left(\tau_{i}, \tau_{t r} ; \bar{r}, X\right)$ has a unique maximum at $\left(\frac{1}{4}, \frac{1}{4}\right)$, for $X$ large enough.

By observation of (2.19), it is clear that the young can benefit from output growth only through the consequent growth in pension benefits. The growth rate of benefits is indeed equal to the output and wages growth, since the ratio of transfers to wages is constant over time. The utility of the young is therefore increasing in the growth rate of output. Given policy variables, this is increasing with the equilibrium value of the marginal productivity of public capital $X$. Using this intuition it is possible to establish the following important result:

Proposition 2. There exists a value of the marginal productivity of public capital $\underline{X}$, such that, if and only if $X>\underline{X}$ the maximization problem (2.19) yields an interior solution, $\left(\tau_{i}^{*}, \tau_{t r}^{*}\right)$, with $\tau_{i}^{*} \in\left(0, \frac{1}{4}\right], \tau_{t r}^{*} \in\left(0, \frac{1}{4}\right]$.

Proof. By Lemma 2 we know that $\left(\tau_{i}^{*}, \tau_{t r}^{*}\right)=\left(\frac{1}{4}, \frac{1}{4}\right)$ is the unique absolute maximum of (2.19), as $X \rightarrow+\infty$. Since the first term in $W$ is decreasing in $\tau_{i}$ and $\tau_{t r}$, it turns out that interior solutions are such that $\tau_{i}^{*} \in\left(0, \frac{1}{4}\right], \tau_{t r}^{*} \in\left(0, \frac{1}{4}\right]$. A sufficient condition for $W\left(\tau_{i}, \tau_{t r} ; \bar{r}, X\right)$ to admit interior solutions is:

$$
W\left(\frac{1}{4}, \frac{1}{4} ; \bar{r}, X\right)=\left(\frac{1+\bar{r}}{2}+\frac{1}{8}+\frac{1}{64} X\right)>W\left(0,0 ; \bar{r}, \alpha, \delta_{K}\right)=(1+\bar{r})
$$


which is satisfied for $X-24-32 \bar{r}>0$. Therefore, if $X>\bar{X}=24+32 \bar{r}$, the solution to (2.19) will be an interior one. Note that, as $X \rightarrow 0$, the unique solution to (2.19) is $(0,0)$, since $\left(1-\tau_{i}-\tau_{t r}\right)\left(1+\bar{r}+\tau_{t r}\right)<(1+\bar{r}) \forall\left(\tau_{i}, \tau_{t r}\right) \neq(0,0)$. Now take $X$ sufficiently small to obtain $\left(\tau_{i}^{*}, \tau_{t r}^{*}\right)=(0,0)$ and consider decreasing values of $X$. Notice that neither $\tau_{i}^{*}$ nor $\tau_{t r}^{*}$ can ever take values above zero as $X$ decreases, since the first term in (2.19) is monotonically decreasing in $\tau_{i}$ and $\tau_{t r}$. Therefore, there exists a threshold $\underline{X} \leq \bar{X}$ such that for $X \leq \underline{X}$, the solution to $(2.19)$ is $(0,0)$, while for $X>\underline{X}$, the solution to $(2.19)$ is $\left(\tau_{i}^{*}, \tau_{t r}^{*}\right)$ with $\tau_{i}^{*} \in\left(0, \frac{1}{4}\right], \tau_{t r}^{*} \in\left(0, \frac{1}{4}\right]$.

The above results make clear that an equilibrium with positive taxation and growth may or may not exist, depending on whether the gains from growth, that the young enjoy in presence of pension benefits, are sufficiently large so that they prefer the equilibrium with positive growth to the no-growth equilibrium.

For given policy variables, the size of such gains increases with the equilibrium value of the marginal productivity of public capital, $X$. The role of parameters, $\left(\delta_{K}, \Delta, \alpha\right)$, and the interest rate, $\bar{r}$, in determining how large is $X$ will be investigated in the following section. Notice also that the constancy of $X$ at equilibrium, as implied by equation (2.15), ensures that the conditions for the existence of an equilibrium with sustained positive growth are not put at stake by the accumulation process.

Moreover, in our set up, positive growth rates can arise only if some share of the total tax revenue is allocated to social security. In fact, positive growth requires positive public investment at each point in time. This in turn requires the share of public investment in after tax income to be positive. Since the young can reap part of the benefits deriving from investment in public capital only through the revaluation of future pensions payments, public investment in after tax income can only be positive if the share of transfers in after tax income is also positive, since this ensures that positive levels of pensions will be paid in the future.

We are now ready to prove the main result of this section:

Proposition 3. If and only if $X>\underline{X}, \sigma_{t}^{*}\left(h_{t}\right)$ is a subgame-perfect Nash equilibrium of the infinitely repeated game $\Gamma(\infty)$. 
How can we characterize the competitive equilibrium associated with the equilibrium outcome $\left(\overline{\tau_{i}}, 0, \tau_{i}^{*}, \tau_{t r}^{*}, \tau_{i}^{*}, \tau_{t r}^{*}, \ldots\right)$ ? First of all, note that the sequences of equilibrium levels of public investment and social security expenditure are given by:

$$
\begin{aligned}
& I_{0}^{g}=\overline{\tau_{i}}\left(1-\overline{\tau_{i}}\right) w_{0} \\
& T R_{0}=0 \\
& I_{t}^{g}=i^{*} w_{t} \text { for } t=1,2, \ldots \infty \\
& T R_{t}=t r^{*} w_{t} \quad \text { for } t=1,2, \ldots \infty
\end{aligned}
$$

Second, note that, since $t=1$, the economy moves along a stationary path where all economic variables grow at the common constant rate:

$$
x^{*}=i^{*} X
$$

where $i^{*}=\tau_{i}^{*}\left(1-\tau_{i}^{*}-\tau_{t r}^{*}\right)$ and $t r^{*}=\tau_{t r}^{*}\left(1-\tau_{i}^{*}-\tau_{t r}^{*}\right)$ are the constant equilibrium shares of labor income which are devolved, respectively, to public investment and transfers, since $t=1$. Note that $t r^{*}$ can also be interpreted as the equilibrium pension replacement rate on earnings. Moreover, consumption allocations are equal to:

$$
\begin{aligned}
& c_{0}^{0}=\frac{w_{0}}{(1+\beta)}\left[\left(1-\overline{\tau_{i}}\right)+\frac{t r^{*}(1+\bar{x})}{(1+\bar{r})}\right] \\
& c_{1}^{0}=\frac{w_{0} \beta}{1+\beta}\left[(1+\bar{r})\left(1-\overline{\tau_{i}}\right)+t r^{*}(1+\bar{x})\right] \\
& c_{t}^{t}=\frac{w_{t}}{(1+\beta)}\left[\left(1-\tau^{*}\right)+\frac{t r^{*}\left(1+x^{*}\right)}{(1+\bar{r})}\right] \quad \text { for } t=1,2, \ldots \infty \\
& c_{t+1}^{t}=\frac{w_{t} \beta}{1+\beta}\left[(1+\bar{r})\left(1-\tau^{*}\right)+t r^{*}\left(1+x^{*}\right)\right] \quad \text { for } t=1,2, \ldots \infty
\end{aligned}
$$

where $\tau^{*}=\tau_{i}^{*}+\tau_{t r}^{*}$ is the constant contributory tax rate, or, equivalently, the constant level of fiscal pressure, since $t=1$, and $\bar{x}=\overline{\tau_{i}}\left(1-\overline{\tau_{i}}\right) X$ is the growth rate realized between $t=0$ and $t=1$.

Note that our social norm is such that expenditure on public investment is initiated (one period) before expenditure on social security, so that the first generation of old receives zero pensions. This feature of the equilibrium is consistent 
with the history of the introduction of Welfare States in most Western countries, where the birth of social security systems followed the institution of other programs, such as public education and public investment in infrastructure.

It is worthwhile to stress that the adoption of the equilibrium strategy $\sigma^{*}\left(h_{t}\right)$ yields an efficiency gain, because the corresponding competitive equilibrium yields a level of utility for all generations higher than in the equilibrium that we analyzed in the previous subsection, where $\tau_{i}=\tau_{t r}=0$ and there is no growth. Indeed, when $X>\underline{X}$, the young would rather put aside a fraction $\tau^{*}$ of their labor income and receive a fraction $\tau_{t r}^{*}$ of the future income, than not pay any taxes and not receive any transfer. Furthermore, the old generations clearly benefit from the introduction of the social security system.

Going back to the motivation of this work, we would like to interpret our equilibrium as the emergence of a social norm, whereby pensions are paid in every period to the old generations in exchange for their previous investment in activities which benefited the current young. This social norm arises as the equilibrium outcome of the infinitely repeated game, where the credible threat of being punished by not receiving any transfer, in case the norm is violated, makes all generations better off, by following it.

\section{Comparativ e Statics}

In the subgame-perfect Nash equilibrium that arises if the equilibrium strategy $\sigma^{*}\left(h_{t}\right)$ is played by each subsequent generation of taxpayers, public investment, social security expenditure and growth are endogenously and simultaneously determined variables, whose size depends crucially on the equilibrium value of the marginal productivity of public capital in production, $X$, which in turn is uniquely determined, given the interest rate, $\bar{r}$, and the technology parameters, $\delta_{K}, \Delta$ and $\alpha$.

In this section, we study the effects on public investment, social security expenditure and growth of ceteris paribus variations in $\bar{r}, \delta_{K}, \Delta$ and $\alpha$, by investigating the comparative statics properties of this equilibrium, for $t \geq 1$. The main results of this investigation are as follows: (1) the equilibrium value of the marginal 
productivity of public capital $X$ is decreasing with $\bar{r}, \delta_{K}$ and $\alpha$ and is increasing with $\Delta ;(2)$ the equilibrium share of public investment in labor income $i^{*}$ and the equilibrium income growth rate $x^{*}$ respond positively to changes in $\delta_{K}, \Delta$ and $\alpha$ that trigger increases in $X$ and are decreasing with $\bar{r}$; (3) the share of transfers in labor income $t r^{*}$ responds positively to changes in $\delta_{K}, \Delta$ and $\alpha$ that trigger increases in $X$ and is decreasing with $\bar{r}$, if $\bar{r} \geq 0.5$ and/or $X$ is below a threshold value $\widetilde{X}$. When $\bar{r}<0.5$ and $X>\widetilde{X}, t r^{*}$ may respond negatively to changes in $\delta_{K}, \Delta$ and $\alpha$ that trigger increases in $X$ and it may be increasing with $\bar{r}$.

In order to determine how $i^{*}, t r^{*}$ and $x^{*}$ respond to changes in $\bar{r}, \delta_{K}, \Delta$ and $\alpha$, we use the following procedure. First, we study the function $X\left(\bar{r}, \delta_{K}, \Delta, \alpha\right)$ and, in particular, we determine the sign of the partial derivatives of $X$ with respect to $\bar{r}, \delta_{K}, \Delta$ and $\alpha$. Second, we derive a sufficient condition for $\tau_{i}^{*}$ and $\tau_{t r}^{*}$ to be differentiable in $\bar{r}$ and $X$. Whenever this condition is satisfied, the sign of the partial derivatives of $\tau_{i}^{*}$ and $\tau_{t r}^{*}$ with respect to $\bar{r}$ and $X$ can be determined by applying the Implicit Function Theorem (IFT). Third, we combine these results to establish the direction of adjustment of $\tau_{i}^{*}$ and $\tau_{t r}^{*}$ to variations in $\bar{r}, \delta_{K}, \Delta$ and $\alpha$. Finally, we pin down the effects of changes in $\bar{r}, \delta_{K}, \Delta$ and $\alpha$ on $i^{*}, t r^{*}$ and $x^{*}$.

Our first result, which we state without proof, provides some information on the limiting behavior of the function $X\left(\bar{r}, \delta_{K}, \Delta, \alpha\right)$. In particular, it is immediate to show that:

\section{Le mma 3.}

$$
\begin{array}{lll}
\lim _{\delta_{K \rightarrow 0}} X=X_{0}^{\prime \prime}>0 & \lim _{\Delta \rightarrow 0} X=0 \quad \lim _{\alpha \rightarrow 0} X=+\infty \\
\lim _{\delta_{K \rightarrow 1}} X=X_{1}^{\prime \prime}<0 & \lim _{\Delta \rightarrow \infty} X=+\infty & \lim _{\alpha \rightarrow 1} X=0
\end{array}
$$

Consider now the subset of vectors of exogenous variables such that the necessary and sufficient condition for the existence of interior solutions to the maximization problem (2.19) is satisfied, that is restrict attention to choices of $\bar{r}, \delta_{K}, \Delta$ and $\alpha$ such that $X>\underline{X}$.

Then we can prove the following:

Le mma 4. If $X>\underline{X}$, the equilibrium value of the marginal productivity of public capital is strictly greater than one. Moreover: 


$$
\frac{\partial X}{\partial \bar{r}}<0 \quad \frac{\partial X}{\partial \delta_{K}}<0 \quad \frac{\partial X}{\partial \Delta}>0
$$

Proof. From (2.21) it can be verified that interior solutions to (2.19) can be obtained only if $X>1$. It is immediate to check that $X>1$ implies $\frac{\partial X}{\partial \bar{r}}<0$, $\frac{\partial X}{\partial \delta_{K}}<0$ and $\frac{\partial X}{\partial \Delta}>0$

The intuition for the above result is pretty obvious. Recall that the marginal productivity of public capital is the product of two factors: the elasticity of public capital in production, $\alpha$, and the average productivity of public capital, $\phi$. For given $\alpha$, the latter is an increasing function of the private to public capital stock ratio, $\kappa$, which in turn is decreasing with $\bar{r}$ and $\delta_{K}$ and is increasing with $\Delta$.

The sign of the partial derivative of $X$ with respect to $\alpha$, is ambiguous apriori and depends on the exogenous variables. A sufficient condition to obtain a negative overall effect of $\alpha$ on $X$ is given by $\Delta(1-\alpha)>\bar{r}+\delta_{K}$, which we henceforth assume to be satisfied.

Before applying the IFT to determine the sign of the partial derivatives of $\tau_{i}^{*}$ and $\tau_{t r}^{*}$ with respect to $\bar{r}$ and $X$, we need to make sure that $\tau_{i}^{*}$ and $\tau_{t r}^{*}$ are differentiable in $\bar{r}$ and $X$. The following result guarantees that this is indeed the case, at least for $X$ large enough.

Proposition 4. There exists a value of the marginal productivity of public capital, $\widehat{X}>\underline{X}$, such that, if $X>\widehat{X}$, the maximization problem (2.19) yields an interior, unique and differentiable solution, $\left(\tau_{i}^{*}(\bar{r}, X), \tau_{t r}^{*}(\bar{r}, X)\right)$, with $\tau_{i}^{*} \in\left(0, \frac{1}{4}\right]$ and $\tau_{t r}^{*} \in\left(0, \frac{1}{4}\right]$.

\section{Proof. See Appendix B.}

Proposition 4 implies that all the differentiable solutions to (2.19) are also interior solutions. For $\widehat{X}>X>\underline{X}$, there may exist interior and non-differentiable solutions to $(2.19)$.

Henceforth, we restrict our attention to choices of the exogenous variables such that $X>\widehat{X}$. Then, we can prove the following: 
Proposition 5. The partial derivative of the equilibrium public investment tax and of the equilibrium social security tax with respect to the interest rate is strictly negative, while the partial derivative of the equilibrium public investment tax and of the social security tax with respect to the marginal productivity of public capital is strictly positive, for $X<\infty$. Namely, for $X<\infty$, we have:

$$
\begin{array}{cl}
\frac{\partial \tau_{i}^{*}(\bar{r}, X)}{\partial \bar{r}}<0 & \frac{\partial \tau_{i}^{*}(\bar{r}, X)}{\partial X}>0 \\
\frac{\partial \tau_{t r}^{*}(\bar{r}, X)}{\partial \bar{r}}<0 & \frac{\partial \tau_{t r}^{*}(\bar{r}, X)}{\partial X}>0
\end{array}
$$

Moreover:

$$
\begin{array}{ll}
\lim _{X \rightarrow \infty} \frac{\partial \tau_{i}^{*}(\bar{r}, X)}{\partial \bar{r}}=0 & \lim _{X \rightarrow \infty} \frac{\partial \tau_{i}^{*}(\bar{r}, X)}{\partial X}=0 \\
\lim _{X \rightarrow \infty} \frac{\partial \tau_{t r}^{*}(\bar{r}, X)}{\partial \bar{r}}=0 & \lim _{X \rightarrow \infty} \frac{\partial \tau_{t r}^{*}(\bar{r}, X)}{\partial X}=0
\end{array}
$$

Proof. See Appendix B.

To grasp the intuition behind these results, some observations are in order. First, recall that, in equilibrium, the marginal benefit of increasing any of the tax rates, which is the marginal net return from public investment, or, equivalently, the marginal increase in pension income minus one, must be equal to the marginal opportunity cost of increasing any of the tax rates, that is the net rate of return from other forms of investment, $\bar{r}$. Second, note that, in equilibrium, the total tax revenue is increasing with both tax rates, while the marginal tax revenue is decreasing with them. In fact, the marginal increase in revenue following an increase in any of the tax rate is equal to $\left[1-2\left(\tau_{i}^{*}+\tau_{t r}^{*}\right)\right]$, which is positive for $\left(\tau_{i}^{*}, \tau_{t r}^{*}\right) \leq\left(\frac{1}{4}, \frac{1}{4}\right)$ and is decreasing with $\tau_{i}^{*}$ and $\tau_{t r}^{*}$, due to the convex collection cost of taxes. Third, note that, given $\tau_{t r}^{*}$, the marginal benefit of increasing $\tau_{i}^{*}$ is diminishing, since $t r^{*}$ becomes progressively smaller and the total and marginal collection costs of taxes become progressively larger as $\tau_{i}^{*}$ increases. Given $\tau_{i}^{*}$, the marginal benefit of increasing $\tau_{t r}^{*}$, is also diminishing, since $i^{*}$ becomes progressively smaller and the total and marginal collection costs of taxes become progressively larger as $\tau_{t r}^{*}$ increases. Fourth, note that an increase in $\tau_{t r}^{*}\left(\tau_{i}^{*}\right)$ also 
has a cross effect on the marginal benefit of increasing $\tau_{i}^{*}\left(\tau_{t r}^{*}\right)$. The sign of such effect is ambiguous: an increase in $\tau_{t r}^{*}$ implies higher total and marginal collection costs, on one hand, and a larger transfer share, on the other hand, while an increase in $\tau_{i}^{*}$ implies higher total and marginal collection costs, on one hand, and a larger public investment share, on the other hand. However, our results imply that these effects, if negative, are not very large in absolute value.

Starting from an equilibrium situation, an increase in $X$, given $\bar{r}$, increases the rate of growth of labor income and the return on investment in public capital, for given tax rates. As a consequence, the marginal benefit of increasing any of the tax rates becomes larger than the marginal opportunity cost of increasing it. In order to restore the equilibrium, both tax rates must be increased. In fact, this implies a reduction of the marginal benefit of increasing any of the tax rates. On the contrary, an increase in $\bar{r}$, given $X$, pushes the opportunity cost of each additional dollar paid out in taxes up. In order to restore the equilibrium, both tax rates must then be reduced.

Putting together Lemma 4 and Propositions 5, it is immediate to conclude that:

Corollary 1. The equilibrium value of both tax rates is strictly increasing with the total factor productivity and strictly decreasing with the depreciation rate of private capital, the elasticity of public capital in production and the interest rate, for $X<\infty$. Namely, for $X<\infty$, we have:

$$
\begin{array}{llll}
\frac{d \tau_{i}^{*}}{d \bar{r}}<0 & \frac{d \tau_{i}^{*}}{d \delta_{K}}<0 & \frac{d \tau_{i}^{*}}{d \Delta}>0 & \frac{d \tau_{i}^{*}}{d \alpha}<0 \\
\frac{d \tau_{t r}^{*}}{d \bar{r}}<0 & \frac{d \tau_{t r}^{*}}{d \delta_{K}}<0 & \frac{d \tau_{t r}^{*}}{d \Delta}>0 & \frac{d \tau_{t r}^{*}}{d \alpha}<0
\end{array}
$$

Moreover:

$$
\begin{aligned}
& \lim _{X \rightarrow \infty} \frac{d \tau_{i}^{*}}{d z}=0 \quad z=\bar{r}, \Delta, \delta_{K}, \alpha \\
& \lim _{X \rightarrow \infty} \frac{d \tau_{t r}^{*}}{d z}=0 \quad z=\bar{r}, \Delta, \delta_{K}, \alpha
\end{aligned}
$$


Changes of the technology parameters that imply an increase in $X$ lead to higher equilibrium values of both tax rates. Instead, ceteris paribus increases in the interest rate, $\bar{r}$, decrease the equilibrium value of both tax rates, since both the direct effect, through the increased opportunity cost, and the indirect effect, through the reduced value of $X$, push in this direction.

Having characterized the effect of changes in the exogenous variables on the equilibrium tax rates, we now turn our attention on the effect of such changes on the equilibrium shares of labor income which are devoted to public investment and social security and on the equilibrium growth rate of income.

As for the equilibrium public investment share and the equilibrium income growth rate, we can prove the following:

Proposition 6. The equilibrium share of public investment in labor income is strictly increasing with the total factor productivity and strictly decreasing with the depreciation rate of private capital, the elasticity of public capital in production and the interest rate, for $X<\infty$. Namely, for $X<\infty$, we have:

$$
\frac{d i^{*}}{d \Delta}>0 \quad \frac{d i^{*}}{d \delta_{K}}<0 \quad \frac{d i^{*}}{d \alpha}<0 \quad \frac{d i^{*}}{d \bar{r}}<0
$$

Moreover:

$$
\lim _{X \rightarrow \infty} \frac{d i^{*}}{d z}=0 \quad z=\bar{r}, \Delta, \delta_{K}, \alpha
$$

Proof. See Appendix B.

By putting together Proposition 6 and Lemma 4, it is then immediate to conclude that:

Corollary 2. The equilibrium rate of growth of income is strictly increasing with the total factor productivity and strictly decreasing with the depreciation rate of private capital, the elasticity of public capital in production and the interest rate. That is:

$$
\frac{d x^{*}}{d \Delta}>0 \quad \frac{d x^{*}}{d \delta_{K}}<0 \quad \frac{d x^{*}}{d \alpha}<0 \quad \frac{d x^{*}}{d \bar{r}}<0
$$


To grasp the intuition behind these results the following observations are in order.

First, by Proposition 5, we know that changes in the exogenous variables that make investment in public capital more remunerative, relative to investment in private capital, imply a stronger fiscal pressure at equilibrium, since both $\tau_{i}^{*}$ and $\tau_{t r}^{*}$ increase as a consequence of such changes.

Second, note that, given the level of fiscal pressure, such changes also imply that a larger share of tax revenue is allocated to public investment in equilibrium. To verify this statement, let $\tau^{*}=\tau_{i}^{*}+\tau_{t r}^{*}$ denote the equilibrium level of fiscal pressure, and $\eta^{*}$ denote the equilibrium share of tax revenue allocated to public investment. Pension income, can then be rewritten as:

$$
\tau^{*}\left(1-\tau^{*}\right)\left(1-\eta^{*}\right)\left[1+\eta^{*} \tau^{*}\left(1-\tau^{*}\right) X\right]
$$

which, given $\tau^{*}$, is maximized for $\eta^{*}=\frac{1}{2}-\frac{1}{2 \tau^{*}\left(1-\tau^{*}\right) X}$. As $X$ increases, the marginal benefit of increasing $\eta^{*}$ becomes larger. In fact, the partial derivative of the average pension benefit with respect to $\eta^{*},\left[\tau^{*}\left(1-\tau^{*}\right)\right]^{2}\left(1-2 \eta^{*}\right) X-$ $\tau^{*}\left(1-\tau^{*}\right)$, is increasing with $X$, if $\eta^{*} \leq \frac{1}{2}$, as it is indeed the case, since $\tau_{i}^{*} \leq \tau_{t r}^{*}$, in equilibrium.

Third, note that the marginal benefit of increasing $\eta^{*}$ is diminishing, as it can be verified by observing that the second partial derivative of pension income with respect to $\eta^{*}$ is negative. In fact, as $\eta^{*}$ increases, the marginal benefit of increasing $\eta^{*}$, in terms of increased public investment, falls, since the transfer share in labor income becomes progressively smaller, while the marginal cost of increasing $\eta^{*}$, in terms of reduced transfers, increases, since the public investment share in labor income becomes progressively larger. The last two observations imply that, as $X$ increases, $\eta^{*}$ must increase in order to restore the equilibrium.

Starting from an equilibrium situation, increases in $\Delta$, or decreases in $\delta_{K}, \alpha$, or $\bar{r}$, increase $X$. This implies that both $\tau^{*}$ and $\eta^{*}$ increase. This explains why $i^{*}$ and $x^{*}$ both increase, following such changes.

The fact that $i^{*}$ increases, following increases in $\Delta$, or decreases in $\delta_{K}, \alpha$, 
or $\bar{r}$, does not necessarily imply that $t r^{*}$ decreases, as a consequence of such changes. Our intuition goes as follows. We know that, for small $X$ and $\tau^{*}$, the total and marginal collection costs of taxes are also small. Then, the increase in tax revenue associated to increases in $\Delta$, or decreases in $\delta_{K}, \alpha$, or $\bar{r}$, will be large enough to compensate for the reduction in the equilibrium share of revenues allocated to transfers and $t r^{*}$ will be increasing with $\Delta$ and decreasing with $\delta_{K}, \alpha$, and $\bar{r}$. As $X$ and $\tau^{*}$ become progressively larger, the total and marginal collection costs of taxes increase. For some critical value of $X$, they may become so high that the increase in tax revenue no longer compensates for the reduction in the equilibrium share of revenues allocated to transfers and $t r^{*}$ may start to decrease with $\Delta$ and to increase with $\delta_{K}, \alpha$, and $\bar{r}$. This argument suggests that $t r^{*}$ should increase or decrease, following ceteris paribus variations in the exogenous variables, depending on the equilibrium value of the marginal productivity of public capital.

Although the intuition is pretty clear, a general result regarding the sign of the variation of $t r^{*}$ in response to changes in the exogenous variables is hard to establish. Still, we can prove the following:

Proposition 7. If $\bar{r} \geq 0.5$, the equilibrium share of transfers in labor income is strictly increasing with the total factor productivity and strictly decreasing with the depreciation rate of private capital, the elasticity of public capital in production and the interest rate. That is:

$$
\frac{d t r^{*}}{d \Delta}>0 \quad \frac{d t r^{*}}{d \delta_{K}}<0 \quad \frac{d t r^{*}}{d \alpha}<0 \quad \frac{d t r^{*}}{d \bar{r}}<0 \quad \text { if } \bar{r} \geq 0.5
$$

If $\bar{r}<0.5$, there exists a vector of values of the marginal productivity of public capital, $\left[\widetilde{X}_{z}\right], z=\bar{r}, \delta_{K}, \Delta, \alpha, \widehat{X} \leq \widetilde{X}_{z}<\infty$, such that:

$$
\begin{aligned}
& \frac{d t r^{*}}{d z} \leq 0 \quad \widehat{X}<\widetilde{X}_{z} \quad z=\bar{r}, \delta_{K}, \alpha \\
& \frac{d t r^{*}}{d \Delta} \geq 0 \quad \widehat{X}<\widetilde{X}_{\Delta}
\end{aligned}
$$


Moreover:

$$
\begin{array}{ll}
\lim _{X \rightarrow \widetilde{X}_{\Delta}^{-}} \frac{d t r^{*}}{d \Delta}>0 & \lim _{X \rightarrow \widetilde{X}_{\bar{z}}^{-}} \frac{d t r^{*}}{d z}>0 \quad z=\bar{r}, \delta_{K}, \alpha \\
\lim _{X \rightarrow \infty} \frac{d t r^{*}}{d \Delta}<0 & \lim _{X \rightarrow \infty} \frac{d t r^{*}}{d z}>0 \quad z=\bar{r}, \delta_{K}, \alpha
\end{array}
$$

Proof. See Appendix B.

Summing up, our model implies that $x^{*}, i^{*}$ and $t r^{*}$ will comove in response to ceteris paribus changes in the exogenous variable $z$, if $\bar{r} \geq 0.5$ or if $\bar{r}<0.5$ and $\widehat{X}<X<\widetilde{X}_{z}$. When $\bar{r}<0.5$ and $X \geq \widetilde{X}_{z}, t r^{*}$ will move in the opposite direction with respect to $x^{*}$ and $i^{*}$, in response to ceteris paribus variations of $z$, if $X$ tends to $\widetilde{X}_{z}$ from above or if $X$ tends to infinity.

Even if the response of $t r^{*}$ to ceteris paribus variations of $z$ can not be characterized analitically for $\widetilde{X}_{z}<X<\infty$ and $\bar{r}<0.5$, our intuition is that $t r^{*}$ should move in the opposite direction with respect to $x^{*}$ and $i^{*}$ in this range. This intuition is supported by numerical simulations of the model, which indicate that the derivatives of the transfer share function with respect to the exogenous variables change sign at most once as $X$ varies within the range of values such that (2.19) admits interior and differentiable solutions.

Before concluding this section, we want to stress once again the intuition behind the results we obtained.

The emergence of a credible social norm (Welfare State), whereby pensions and public investment are financed in every period by labor income taxation, allows all generations to enjoy the benefits associated to (public-investment driven) growth. The social norm reflects the interests of the current taxpayers and will be modified if the environment changes due to exogenous shocks. In particular, if the marginal productivity of public capital in production increases, it seems reasonable that the social norm should be modified in order to allow the taxpayers to reap the benefit associated to the larger growth potential. Namely, it seems reasonable that the social norm should be modified by increasing the level of fiscal pressure so as to boost public investment, growth and future pensions. 
If the marginal productivity of public capital and, consequently, the level of fiscal pressure and the total and marginal collection costs of taxes are not very large, the social norm should also be modified by increasing the replacement rate on earnings, that is the share of transfers in labor income, since this allows for further increases in future pensions and provides further benefits for the current taxpayers. On the other hand, if the marginal productivity of public capital is large and so are the total and marginal collection costs of taxes, increases in public investment and future pensions can only be obtained by reshuffling the current public expenditure from social security to public investment, that is by reducing the replacement rate on earnings. Note that current pensions will increase along with public investment in the former case, while they will decrease in the latter.

In other words, our model provides an intuitive argument for why an expanding pie can make the distribution conflict between the young and the old less stringent. Since the young can benefit from higher growth only by increasing pensions, the replacement rate on earnings $t r^{*}$ may wind up being increased, along with public investment and growth, so that both current and future pensions increase, in order to exploit an expanding growth potential. This is less likely to happen, the larger the costs of running the Welfare State.

\section{Conclusion}

The present paper puts forward an explanation for why redistributive and growthoriented policies, though competing for scarce tax revenues, might go hand in hand and bring about fast economic growth.

Our model analyzes the case of a small open economy where sustained growth is generated by public investment in capital goods financed through tax revenues. In this context, a mechanism of intergenerational transfers, such a pure pay-asyou-go social security system, that is one where pension benefits are fully indexed to wages, may provide the taxpayers with the right incentives to support growthoriented policies, such as investment in infrastracture or public education.

We think it is important to stress that a fully-funded social security system would not guarantee the same result. Indeed, in a small open economy where 
capital is perfectly mobile, the rate of return from the portion of savings accruing to a fully-funded system, which is equal to the market interest rate, is fixed at the worldwide level and is independent from the accumulation of domestic capital. Thus, in this case, agents cannot expect to benefit from the growth process through an increase of the future return on their savings. Instead, the accumulation process will certainly affect the return on their contributions to a pay-asyou-go system, through the increased productivity of labor and, consequently, the higher level of future wages.

Two are the main results of the paper. First, we showed that, whenever the marginal productivity of public capital in the private sector is large enough, an outcome characterized by positive levels of redistribution and public investment and by sustained positive growth can be supported as a subgame-perfect Nash equilibrium of an infinitely repeated intergenerational game, where at each stage the young choose the level of fiscal policies, taking into account the past histories of the game and the consequences of their actions on those of future generations. The credible threat to be denied the entitlement to pensions in old age by the following generation deters the young from defaulting on the social norm.

Second, we showed that in a neighborhood of the equilibrium with positive growth, given a change in the exogenous variables: (a) the share of public investment in labor income and the rate of growth move in the same direction; (b) depending on whether the marginal productivity of public capital is below or above a certain threshold, the share of transfers in labor income (that is, the replacement rate) and the rate of growth either comove or move in the opposite direction. 


\section{$R$ eferences}

[1] Alesina, A., and D. Rodrick (1993), " Distributive Politics and Economic Growth", forthcoming in the Quarterly Journal of Economics.

[2] Ashauer, D.A. (1989), "Is Public Expenditure Productive?", Journal of Monetary Economics, 23, 177-200.

[3] Barro, R., (1990) "Government Spending in A Simple Model of Endogenous Growth", Journal of Political Economy, 98, 103-125.

[4] _-- (1991), "Economic Growth in A Cross Section of Countries", Quarterly Journal of Economics, 106, 407-444.

[5] _-- and X. Sala-y-Martin (1991), "Public Finance in Models of Economic Growth", Harvard University, mimeo.

[6] Becker, G. (1993), A Treatise on the Family, Harvard University Press: Cambridge, Massachusetts.

[7] Bertola, G., (1993), "Factor Shares, Income Distribution and Economic Growth", American Economic Review, 83(5), 1184-1210.

[8] Boadwin, R., and D. Wildasin (1989a), "Voting Models of Social Security Determination", in: B.A. Gustaffson and Klevmarken, N.A. eds. The Political Economy of Social Security, North-Holland, Amsterdam.

[9] _-_ and _-_ (1989b), "A Median Voter Model of Social Security", International Economic Review, 30, 307-328.

[10] Boldrin, M. (1992), "Public Education and Capital Accumulation", D.P. 1017, Northwestern University.

[11] Boldrin, M. and A. Rustichini (1995), "Equilibria with Social Security", mimeo. 
[12] Browning, E.K. (1975), "Why The Social Insurance Budget is Too Large in A Democratic Society?", Economic Inquiry, 13, 373-388.

[13] Canning, D., Fay, M. and R. Perotti (1992), "Infrastructure and Growth", mimeo, Columbia University.

[14] Cukierman, A., and A. Meltzer (1989), "A Political Theory of Government Debt and Deficits in the Neo-Ricardian Framework", American Economic Review, 79, 713-732.

[15] Easterly, W.R. and D.L. Wetzel (1989), "Policy Determinants of Growth", mimeo.

[16] Katzenstein, (1984)

$[17]--(1985)$

[18] Kotlikoff, L. T. Persson and L. Svensson (1988) "Social Contracts and Assets: A Possible Solution to the Time Consistency Problem", American Economic Review, 78(4), 662-677.

[19] Krusell, P. and J.V. Rios-Rull (1994), "What Constitutions Promote Capital Accumulation? A Political-Economy Approach", mimeo, University of Pennsylvania.

[20] Krusell, P., Quadrini, V. and J.V. Rios-Rull (1994), "Politico-Economic Equilibrium and Economic Growth", forthcoming in the Journal of Economic Dynamics and Control.

[21] Hu, S.C. (1982), "Social Security, Majority-Voting Equilibrium and Dynamic Efficiency", International Economic Review, 23, 269-287.

[22] Perotti, R. (1992), "Fiscal Policy, Income Distribution, and Growth", mimeo, Columbia University.

[23] _-- (1993), "Political Equilibrium, Income Distribution and Growth", Review of Economic Studies, 60(4), 755-766. 
[24] Persson, T. and G. Tabellini (1994), "Is Inequality Harmful for Growth: Theory and Evidence", American Economic Review, 84(3), 600-621.

[25] Rimlinger, G.V. (1971), Welfare Policy and Industrialization in Europe, America and Russia, New York: John Wiley.

[26] Sachs, J. (1989), "Social Conflict and Populist Policies in Latin America", NBER W.P. 2897.

[27] Samuelson, P. (1975), "Optimum Social Security in a Life-Cycle Growth Model", International Economic Review, 16, 539-544.

[28] Sjoblom, K. (1985), "Voting for Social Security", Public Choice, 45, 225-240.

[29] Sala-y-Martin, X. (1992), "Bribery in Macroeconomics", mimeo, Yale University.

[30] Tabellini, G., (1990), "A Positive Theory of Social Security", NBER W.P. 3272 .

[31] Verbon, H.A.A. (1986), "Altruism, Political Power and Public Pensions", Kyklos, 39, 343-358.

[32] _-- (1990), "The Rise and Evolution of Public Pensions System", Public Choice

[33] White, H., (1980), "A Heteroschedasticity-Consistent Covariance Matrix Estimator and a direct test for Heteroschedasticity", Econometrica, 48, 817-838.

\section{A pp endix A}

\section{Proof of Proposition 3}

In this appendix, we want to show that, given any possible history of the game, if and only if $X>\underline{X}$, no generation has an incentive to unilaterally deviate from strategy $s_{t}^{*}$, that is, this strategy represents a subgame-perfect Nash equilibrium of the intergenerational game that we have described in section 3 . 
First, consider the young generation at time $t$ when, in the previous period, the coexisting old have set $\tau_{t r, t-1}=\tau_{t r}^{*}$ and $\tau_{i, t-1}=\tau_{i}^{*}$, that is $h_{t}=\left(\cdot, \tau_{i}^{*}, \tau_{t r}^{*}\right)$. If the young play according to strategy $s_{t}^{*}$, their lifetime income will be equal to:

$$
W_{F}^{t}=\frac{w_{t}}{(1+\bar{r})}\left[\left(1+\bar{r}+\tau_{t r}^{*}\right)\left(1-\tau_{i}^{*}-\tau_{t r}^{*}\right)+\tau_{t r}^{*} \tau_{i}^{*}\left(1-\tau_{i}^{*}-\tau_{t r}^{*}\right)^{2} X\right]
$$

On the other hand, expecting all other generations to adopt the strategy $s_{t}^{*}$, the best possible deviation for the young is to set both public investment and transfers equal to zero. In this case, their lifetime income is given simply by:

$$
W_{B}^{t}=w_{t}
$$

which is always smaller than $W_{F}^{t}$ if the necessary and sufficient condition for the existence of an interior equilibrium holds, i.e. $X>\underline{X}$.

Let us now consider the case where $h_{t}=\left(\cdot, \tau_{i}^{\prime}, \tau_{t r}^{\prime}\right)$ and $N$ is even. Clearly, if the young follows the equilibrium strategy, their utility is equal to $W_{F}^{t}$, whereas if they deviate, they will be punished by the following generation and the highest level of utility that they can obtain is $W_{B}^{t}$.

Finally, consider the case where $h_{t}=\left(\cdot, \tau_{i}^{\prime}, \tau_{t r}^{\prime}\right)$ and $N$ is odd. Here, we must show that the young have always an incentive to punish the coexisting old. Indeed, if the young adopt the strategy $s_{t}^{*}$ their utility will be equal to:

$$
W_{P}^{t}=\frac{w_{t}}{(1+\bar{r})}\left[\left(1-\bar{\tau}_{i}\right)(1+\bar{r})+\tau_{t r}^{*}\left(1-\tau_{i}^{*}-\tau_{t r}^{*}\right)\left[1+\bar{\tau}_{i}\left(1-\bar{\tau}_{i}\right) X\right]\right]
$$

By construction of $\bar{\tau}_{i}$, this is the maximum level of utility that the young can reach when the future policies are $\left(\tau_{i}^{*}, \tau_{t r}^{*}\right)$.

The last argument can be also used to show that the first generation does not have any incentive to deviate from the strategy $\sigma_{t}^{*}$, which concludes the proof. 


\section{A pp endix B}

\section{Proof of Proposition 4}

We decided to omit this proof from the text, since it is not relevant for the following discussion. This proof is available from the authors upon request.

\section{Proof of Proposition 5}

Denote the matrix of second partial derivatives of $W\left(\tau_{i}, \tau_{t r} ; \bar{r}, X\right)$, calculated at $\left(\tau_{i}^{*}(\bar{r}, X), \tau_{t r}^{*}(\bar{r}, X)\right)$, by $\Omega_{2 \times 2}$. The generic element of $\Omega_{2 \times 2}$ is then:

$$
W_{a b}=\frac{\partial^{2}}{\partial \tau_{a} \partial \tau_{b}} W\left(\tau_{i}^{*}(\bar{r}, X), \tau_{t r}^{*}(\bar{r}, X) ; \bar{r}, X\right)
$$

where $a=(i, t r)$ and $b=(i, t r)$.

For $X>\widehat{X}$, the solutions to the maximization problem (2.19) are interior and differentiable, by Proposition 4. Then, we can apply the IFT to derive the expressions for the partial derivatives of $\tau_{i}^{*}$ and $\tau_{t r}^{*}$ with respect to $\bar{r}$ and $X$. In particular, these are given by:

$$
\begin{array}{ll}
\frac{\partial \tau_{i}^{*}}{\partial \bar{r}}=\frac{W_{t r t r}-W_{i t r}}{|\Omega|} & \frac{\partial \tau_{t r}^{*}}{\partial \bar{r}}=\frac{W_{i i}-W_{i t r}}{|\Omega|} \\
\frac{\partial \tau_{i}^{*}}{\partial X}=\frac{-W_{i X} W_{t r t r}+W_{t r X} W_{i t r}}{|\Omega|} & \frac{\partial \tau_{t r}^{*}}{\partial X}=\frac{-W_{t r X} W_{i i}+W_{i X} W_{i t r}}{|\Omega|}
\end{array}
$$

where:

$$
\begin{aligned}
& W_{i i}=-2 \tau_{t r}^{*} X\left(2-3 \tau_{i}^{*}-2 \tau_{t r}^{*}\right) \\
& W_{t r t r}=-2\left[1+\tau_{i}^{*} X\left(2-2 \tau_{i}^{*}-3 \tau_{t r}^{*}\right)\right] \\
& W_{i t r}=W_{t r i}=\left[\left(1-\tau_{i}^{*}-\tau_{t r}^{*}\right)\left(1-3 \tau_{i}^{*}-3 \tau_{t r}^{*}\right)+2 \tau_{i}^{*} \tau_{t r}^{*}\right] X-1 \\
& W_{i X}=\left(1-\tau_{i}^{*}-\tau_{t r}^{*}\right) \tau_{t r}^{*}\left(1-3 \tau_{i}^{*}-\tau_{t r}^{*}\right) \\
& W_{t r X}=\left(1-\tau_{i}^{*}-\tau_{t r}^{*}\right) \tau_{i}^{*}\left(1-\tau_{i}^{*}-3 \tau_{i}^{*}\right) \\
& |\Omega|=\operatorname{det}(\Omega)=W_{i i} W_{t r t r}-\left(W_{i t r}\right)^{2}
\end{aligned}
$$


and all functions and derivatives are evaluated at $\left(\tau_{i}^{*}(\bar{r}, X), \tau_{t r}^{*}(\bar{r}, X)\right)$.

By Proposition 4, we know that $W_{i i}<0, W_{\text {trtr }}<0,|\Omega|>0$. Moreover, Lemma 2 implies $\lim _{X \rightarrow \infty}\left(\tau_{i}^{*}(\bar{r}, X), \tau_{t r}^{*}(\bar{r}, X)\right)=\left(\frac{1}{4}, \frac{1}{4}\right)$. Some algebra also permits to verify that $\left(W_{i t r}-W_{t r t r}\right)$ and $\left(W_{i t r}-W_{i i}\right)$ are strictly positive at all interior solutions.

It is then immediate to verify that $\frac{\partial \tau_{i}^{*}}{\partial \bar{r}}<0, \frac{\partial \tau_{t r}^{*}}{\partial \bar{r}}<0$, for $X<\infty$ and that $\lim _{X \rightarrow \infty} \frac{\partial \tau_{i}^{*}}{\partial X}=0, \lim _{X \rightarrow \infty} \frac{\partial \tau_{t r}^{*}}{\partial X}=0$. By using numerical calculations, it is also possible to check that $\lim _{X \rightarrow \infty} \frac{\partial \tau_{i}^{*}}{\partial \bar{r}}=0$ and $\lim _{X \rightarrow \infty} \frac{\partial \tau_{t r}^{*}}{\partial \bar{r}}=0$.

Now use (2.23) and (6.1) to obtain:

$$
\begin{aligned}
& \frac{\partial \tau_{i}^{*}}{\partial X}=\frac{\left[\tau_{i}^{*}\left(1-\tau_{i}^{*}-3 \tau_{t r}^{*}\right)\left(W_{i t r}-W_{t r t r}\right)-\frac{W_{t r t r}}{X}\right] \cdot\left(1-\tau_{i}^{*}-\tau_{t r}^{*}\right)}{|\Omega|} \\
& \frac{\partial \tau_{t r}^{*}}{\partial X}=\frac{\left[\tau_{i}^{*}\left(1-\tau_{i}^{*}-3 \tau_{t r}^{*}\right)\left(W_{i t r}-W_{i i}\right)+\frac{W_{i t r}}{X}\right] \cdot\left(1-\tau_{i}^{*}-\tau_{t r}^{*}\right)}{|\Omega|}
\end{aligned}
$$

from which we can immediately conclude that $\frac{\partial \tau_{i}^{*}}{\partial X}>0$, for $X<\infty$.

By making use of (2.21) and (2.22), the numerator of $\frac{\partial \tau_{t r}^{*}}{\partial X}$ can be rewritten as:

$$
\begin{aligned}
& -\tau_{t r}^{*}\left(1-3 \tau_{i}^{*}-\tau_{t r}^{*}\right)+\left(1+\bar{r}+\tau_{t r}^{*}\right)\left[\left(1-3 \tau_{i}^{*}-3 \tau_{t r}^{*}\right)+\frac{2 \tau_{i}^{*} \tau_{t r}^{*}}{1-\tau_{i}^{*}-\tau_{t r}^{*}}\right]+ \\
& +2 \tau_{t r}^{*}\left(2-3 \tau_{i}^{*}-2 \tau_{t r}^{*}\right)\left(\frac{\tau_{i}^{*}+\bar{r}+2 \tau_{t r}^{*}}{1-\tau_{i}^{*}-\tau_{t r}^{*}}\right)
\end{aligned}
$$

which, by numerical calculations, can be verified to be strictly positive for $\left(\tau_{i}^{*}, \tau_{t r}^{*}\right)$ $<\left(\frac{1}{4}, \frac{1}{4}\right)$, so that we can conclude that $\frac{\partial \tau_{t r}^{*}}{\partial X}>0$, for $X<\infty$.

\section{Proof of Proposition 6}

Proposition 4 and Corollary 1 imply that $\left(1-3 \tau_{i}^{*}-\tau_{t r}^{*}\right) \frac{d \tau_{i}^{*}}{d z}<0, z=\bar{r}, \delta_{K}, \alpha$ and $\left(1-\tau_{i}^{*}-3 \tau_{t r}^{*}\right) \frac{d \tau_{i}^{*}}{d \Delta}>0$, if $\widehat{X}<X<\infty$. 
have:

There are two possible cases: either $\frac{d \tau_{i}^{*}}{d \tau_{t r}^{*}} \leq 1$ or $\frac{d \tau_{i}^{*}}{d \tau_{t r}^{*}}>1$. In the former, we

$$
\begin{aligned}
& d i^{*} \leq\left(1-3 \tau_{i}^{*}-\tau_{t r}^{*}\right) d \tau_{t r}^{*} \\
& d t r^{*} \geq\left(1-\tau_{i}^{*}-3 \tau_{t r}^{*}\right) d \tau_{i}^{*}
\end{aligned}
$$

while, in the latter, we have:

$$
\begin{gathered}
d i^{*}>\left(1-3 \tau_{i}^{*}-\tau_{t r}^{*}\right) d \tau_{t r}^{*} \\
d t r^{*}<\left(1-\tau_{i}^{*}-3 \tau_{t r}^{*}\right) d \tau_{i}^{*}
\end{gathered}
$$

Now use (2.23) to write $i^{*}=t r^{*}-\frac{1}{X}$ and obtain:

$$
\frac{d i^{*}}{d z}=\frac{d t r^{*}}{d z}+\frac{1}{X^{2}} X_{z} \quad z=\bar{r}, \Delta, \delta_{K}, \alpha
$$

By Corollary 1, we know that $\frac{d \tau_{i}^{*}}{d \Delta}>0, \frac{d \tau_{t r}^{*}}{d \Delta}>0, \frac{d \tau_{i}^{*}}{d z}<0$ and $\frac{d \tau_{t r}^{*}}{d z}<0 z=$ $\bar{r}, \delta_{K}, \alpha$. By combining these results and by using (6.1), (6.2), (6.3) and Lemma 4 , it is easily verified that $\frac{d i^{*}}{d \Delta}>0$ and $\frac{d i^{*}}{d z}<0 z=\bar{r}, \delta_{K}, \alpha$, for $\widehat{X}<X<\infty$. It is also immediate to verify that $\lim _{X \rightarrow \infty} \frac{d i^{*}}{d z}=0$ for $z=\bar{r}, \delta_{K}, \Delta, \alpha$.

\section{Proof of Proposition 7}

The derivative of the transfer share function with respect to any of the exogenous variables is given by:

$$
\frac{d t r^{*}}{d z}=\left(1-\tau_{i}^{*}-2 \tau_{t r}^{*}\right) \frac{d \tau_{t r}^{*}}{d z}-\tau_{t r}^{*} \frac{d \tau_{i}^{*}}{d z}
$$

Let $\bar{C}(X, \bar{r})=\frac{1-2 \tau_{i}^{*}-\tau_{t r}^{*}}{\tau_{t r}^{*}}, \underline{C_{z}}(X, \bar{r})=\frac{d \tau_{i}^{*} / d z}{d \tau_{t r}^{*} / d z}$ and $D_{z}(X, \bar{r})=\bar{C}(X, \bar{r})-$ $\underline{C}_{z}(X, \bar{r})$. Then we have:

$$
\begin{aligned}
& \operatorname{sign} \frac{d t r^{*}}{d \Delta}=\operatorname{sign} D_{\Delta} \\
& \operatorname{sign} \frac{d t r^{*}}{d z}=\operatorname{sign}\left(-D_{z}\right) \quad z=\bar{r}, \delta_{K}, \alpha
\end{aligned}
$$


When $\bar{r} \geq 0.5$, it can be verified that $D_{z}(X, \bar{r})$ is strictly positive at all interior solutions. Therefore we can conclude that, if $\bar{r} \geq 0.5$, then $\frac{d t r^{*}}{d \Delta}>0$ and $\frac{d t r^{*}}{d z}<0$, $z=\bar{r}, \delta_{K}, \alpha$, for all $X$ such that $X>\widehat{X}$.

By studying the limiting behavior of the functions $\bar{C}(X, \bar{r})$ and $\underline{C}(X, \bar{r})$, it can be verified that $\lim _{X \rightarrow \infty} \bar{C}(X, \bar{r})=1$ and, for $\bar{r}<0.5, \lim _{X \rightarrow \infty} \underline{C}_{z}(X, \bar{r})=\underline{C}_{z}^{\prime}>$ 1. Therefore, if $\bar{r}<0.5$, we can conclude that, $\lim _{X \rightarrow \infty} \vec{D}_{z}(X, \bar{r})=D_{z}^{\prime}<0$, $\lim _{X \rightarrow \infty} \frac{d t r^{*}}{d \Delta}=t r_{\Delta}^{\prime}<0$ and $\lim _{X \rightarrow \infty} \frac{d t r^{*}}{d z}=t r_{z}^{\prime}>0, z=\bar{r}, \delta_{K}, \alpha$. By Proposition 4 , all the differentiable solutions to $(2.19)$ are interior solutions. Therefore, the functions $\bar{C}(X, \bar{r})$ and $\underline{C}(X, \bar{r})$ are not defined at $\left(\tau_{i}^{*}(X, \bar{r}), \tau_{t r}^{*}(X, \bar{r})\right)=(0,0)$. Still, if $\left(\tau_{i}^{*}(\widehat{X}, \bar{r}), \tau_{t r}^{*}(\widehat{X}, \bar{r})\right) \rightarrow(0,0)$, it can be verified that $\bar{C}(\widehat{X}, \bar{r}) \rightarrow \infty$ and $\underline{C}_{z}(\widehat{X}, \bar{r}) \rightarrow \underline{C}_{z}^{\prime \prime} \ll \infty$, so that $D_{z}(\widehat{X}, \bar{r}) \rightarrow \infty$.

By observing the limiting behavior of the function $D_{z}(X, \bar{r})$ and by the continuity of $\tau_{i}^{*}(\widehat{X}, \bar{r}), \tau_{t r}^{*}(\widehat{X}, \bar{r})$ and $D_{z}(X, \bar{r})$, which is also guaranteed by Proposition 4 , we can conclude that, if $\bar{r}<0.5$, there exists a vector of values of the marginal productivity of public capital, $\left[\widetilde{X}_{z}\right], z=\bar{r}, \delta_{K}, \Delta, \alpha, \widehat{X}<\widetilde{X}_{z}<\infty$, such that $D_{z}\left(\widetilde{X}_{z}, \bar{r}\right)=0, D_{z}(X, \bar{r}) \geq 0$ for $X<\widetilde{X}_{z}$ and $\lim _{X \rightarrow \widetilde{X}_{\bar{z}}^{-}} D_{z}(X, \bar{r}) \leq 0$.

Therefore we can conclude that, if $\bar{r}<0.5$, there exists a vector of values of the marginal productivity of public capital, $\left[\widetilde{X}_{z}\right], z=\bar{r}, \delta_{K}, \Delta, \alpha, \widehat{X}<\widetilde{X}_{z}<\infty$, such that $\frac{d t r^{*}}{d z}=0$ for $X=\widetilde{X}_{z}, \frac{d t r^{*}}{d z} \leq 0, z=\bar{r}, \delta_{K}, \alpha, \frac{d t r^{*}}{d \Delta} \geq 0$ for $X<\widetilde{X}_{z}$, and $\lim _{X \rightarrow \widetilde{X}_{\bar{z}}^{-}} \frac{d t r^{*}}{d z} \geq 0, z=\bar{r}, \delta_{K}, \alpha, \lim _{X \rightarrow \widetilde{X}_{\bar{z}}^{-}} \frac{d t r^{*}}{d \Delta} \leq 0$.

In order to test the reasonability of the assumption by which $D_{z}(\widehat{X}, \bar{r})>0$, $z=\bar{r}, \delta_{K}, \Delta, \alpha$, we estimated the value of the function $D_{z}(X, \bar{r})$ at $\widehat{X}_{\epsilon}$, where $\widehat{X}_{e}$ is defined as the minimum value of $X$ such that an interior and differentiable solution to $(2.19)$ can be calculated numerically, and found that $D_{z}\left(\widehat{X}_{e}, \bar{r}\right)>0$, $z=\bar{r}, \delta_{K}, \Delta, \alpha$. 